\title{
Promising recent advances in preterm birth management
}

\author{
Miss Georgia N Ross ${ }^{1 *}$, Alexandra E Ridout ${ }^{2}$ and Andrew H Shennan ${ }^{2}$ \\ ${ }^{1}$ The University of Newcastle, University Dr. Callaghan NSW 2308, Australia \\ ${ }^{2}$ Division of Women's Health, King's College London, St Thomas' Hospital, Westminster Bridge Road, London, United Kingdom
}

\begin{abstract}
Preterm birth is the leading cause of perinatal and neonatal morbidity and mortality worldwide and continues to have significant impact. Exciting new advances in diagnostic and preventative strategies are providing the potential for clinicians to treat patients based on individualised risk. These include quantification of fetal fibronectin and its use in combination with cervical length measurement to predict risk of imminent delivery, and further exploration of biochemical tests that may be used to aid prediction and risk stratification. New research into preventative strategies centres on developing knowledge and understanding of cervical cerclage, progesterone and the Arabin pessary. Latest investigation of methods for reactive management is altering the way that women are treated once preterm birth is imminent. This review article will discuss some of the more promising advances that have occurred in the last decade.
\end{abstract}

Abbreviations: OR: Odds Ratio; CI: Confidence Interval; RR: Relative Risk; NPV: Negative Predictive Value; PPV: Positive Predictive Value

\section{Introduction}

There is an increased focus in medicine on risk-based individualisation of care, such as when to apply treatment or preventative intervention, and for whom [1]. Exciting new advances in diagnostic and preventative strategies for preterm birth reflect this focus, and are driving clinicians towards personalised care. Appropriate predictive tests are increasingly accessible and current research is evaluating different treatment modalities. Better than ever before, the clinician is able to reassure, reduce unnecessary interventions and target treatment where it is needed most.

Preterm birth, defined as spontaneous or iatrogenic delivery before 37 weeks gestation is the leading cause of perinatal and neonatal morbidity and mortality worldwide [2]. A phenomenon that is estimated to occur in $11.1 \%$ of all pregnancies globally, preterm birth results in the deaths of more than one million children in the world every year [3]. Of those that survive, many will face significant long-term physical and neurodevelopmental morbidity. This includes greater risk of cerebral palsy, intellectual impairment, chronic lung disease, vision and hearing loss.

Traditionally perceived as a single condition, there is a growing realisation that preterm labour is a multifactorial and complex syndrome [4] precipitated by varying aetiologies which include one or a combination of infection, steroid hormone imbalance, uterine over distension, cervical insufficiency and placental vascular pathology. Root cause also needs to be considered and managed, such as recreational drug use, smoking and domestic violence.

Current management focuses on identifying at risk cases and instigating intervention. Options include cervical cerclage, progesterone therapy or insertion of an Arabin pessary. When delivery is inevitable, strategies to improve neonatal outcome such as in utero transfer (IUT), administration of antenatal corticosteroids (ACS) and magnesium sulphate are important.
Many women have no risk factors and are only identified when they present with threatened preterm labour (TPTL). The majority of women who present like this do not go on to deliver until term, and only a small minority deliver within a week of presentation [5]. As such, accurate prediction and stratification into different risks is essential if we are going to target our intervention appropriately. Knowing when it is safe to withhold intervention and reassure is important as this affects the majority of women, and can have huge human and economic cost saving benefits.

\section{Risk factors}

Previous preterm birth is the most significant risk factor for repeat preterm birth [6], although several pre-pregnancy maternal risk factors have been identified. These include previous late miscarriage, previous invasive cervical surgery, uterine abnormalities, black ethnicity, maternal smoking, vaginal infections, low body mass index (BMI) and low socioeconomic status [7]. Preterm birth rates for women of black, African-American and Afro-Caribbean ethnicity are 16-18\% compared with $5-9 \%$ for white women [7]. Other maternal demographics associated with spontaneous preterm birth (sPTB) include high levels of stress, low socioeconomic status, extremes of maternal age and single marital status [7]. Unhealthy lifestyle choices indirectly associated with low socioeconomic status are potentially associated with infective aetiologies such as genital tract infection. Similarly, lifestyle factors such as nutritional status (low pre-pregnancy BMI) and smoking increase the risk of sPTB. Indeed, tobacco smoking increases this risk two-fold [8]. Placental damage with decreased blood flow due to

Correspondence to: Georgia N Ross. Medical student, The University of Newcastle, University Dr, Callaghan NSW 2308, Australia, Tel: +44-(0)-207188-3639, Fax:+44-(0)-207-620-227; E-mail: Georgia.ross@uon.edu.au

Key words: preterm birth, prediction, quantitative fetal fibronectin, cervical length

Received: January 29, 2016; Accepted: March 31, 2016; Published: April 04, 2016 
vasoconstriction caused by nicotine and carbon monoxide is thought to underlie this increased risk. Additionally, smoking is associated with a systemic inflammatory response, also implicated in sPTB.

Multiple gestations are well recognised as being at increased risk of prematurity, with nearly $60 \%$ of twins born preterm [7]. The causative mechanism is believed to be uterine over distension leading to contractions and preterm premature rupture of membranes (PPROM).

There is a longstanding association between cervical 'insufficiency' as a result of congenital cervical weakness, conisation or LEEP surgery for cervical intraepithelial neoplasia and trauma, and preterm birth. Inadvertent cervical damage during full dilatation caesarean section (FDCS) has recently received heightened interest, especially as rates of caesarean section continue to increase.

Data published in the AJOG in 2015 highlights a six-fold increase in the odds of having a sPTB compared to first stage lower-segment caesarean section (OR 5.8; 95\% CI, 1.08-30.8; $\mathrm{P}=0.04$ ) [9]. Results of this study raise questions about the optimum management of postFDCS patients, and may inform future research.

Questions have been raised regarding the potential for transabdominal cerclage within this subgroup of patients to support the cervix above the defect caused during FDCS incision. Now that this risk has been identified, there is scope to improve education of clinicians, and therefore labour management in order to reduce the cervical insult at the time of FDCS, as well as recognise and appropriately manage potential risk in subsequent pregnancies.

\section{Prediction}

In the majority of cases (>90\%), women who present with symptoms of preterm labour do not go on to deliver in the next two weeks. Indeed, over half will continue until full term [5]. Ubiquitous treatment of TPTL with tocolysis, ACS, magnesium sulphate and hospital admission is expensive, and can be associated with detrimental side effects, notably thromboembolism as a result of extended hospital admission [10]. Recent NICE guidelines recommend routine admission and treatment of all women with symptoms of preterm labour $<30$ weeks, without diagnostic tests; the potential adverse effects of this were not considered and should be closely audited [11].

Advances in our understanding of biochemical and biophysical markers for PTB have elucidated more accurate methods of risk prediction, and NICE should consider these in the future. As tests improve, we are better placed to identify the patient who is likely to deliver, and thus appropriately target management.

\section{Fetal fibronectin}

Fetal fibronectin (fFN) is a glycoprotein produced by cells between the chorion and decidua. After the fusion of decidua and fetal membranes at 18 weeks, fFN concentrations should be undetectable in cervicovaginal fluid (CVF). However, fFN may be released in the face of inflammatory, infectious or mechanical disturbance to the placenta or membranes. The presence of fFN in high concentrations in the CVF after 23 weeks gestation is associated with sPTB in both symptomatic and high-risk asymptomatic women [12].

CVF samples are collected with a swab placed in the posterior fornix of the vagina for 10 seconds during sterile vaginal speculum examination. Originally analysed in a laboratory, the sample can now be measured using a bedside automated instrument (TLiIQ, Hologic) or with a visually interpreted dipstick test (QuikCheck, Hologic).
Intercourse in the previous 48 hours or vaginal bleeding can falsely elevate results and are therefore contraindications to performing the test.

Recent data supports the enhanced predictive value of quantitative fetal fibronectin (qfFN), a measure of the absolute concentration of fFN in CVF, rather than the traditional qualitative test, with a positive and negative result based around a threshold of $50 \mathrm{ng} / \mathrm{ml}[13,14]$. Chosen as the point representing a medium between optimal sensitivity and specificity, the greatest value of the $50 \mathrm{ng} / \mathrm{ml}$ threshold lies in its high negative predictive value, largely due to the low prevalence of the studies evaluated. There is a need to improve its sensitivity and specificity. Improved predictive statistics can be achieved by changing the threshold. In their examination of qfFN, Kurtzman et al. demonstrated that relative risk for $\mathrm{PPTB}$ increased with each rising threshold. Compared with a fFN of $0 \mathrm{ng} / \mathrm{mL}$, the relative risk for sPTB $<34$ weeks at a fFN concentration $>200 \mathrm{ng} / \mathrm{mL}$ was 9.9 (95\% CI, 2.90 19.67) for women of 24 weeks gestation with at least one previous preterm birth [15].

The EQUIPP study (Evaluation of a Quantitative Instrument for the Prediction of Preterm Birth) prospectively evaluated quantification of $\mathrm{fFN}$ in a large number of high risk patients $(\mathrm{n}=1448)$. It was demonstrated that the use of varying fFN thresholds $(10,50,200$ and $500 \mathrm{ng} / \mathrm{ml}$ ) enhanced the PPV for $\mathrm{SPTB}$ as the threshold increases, whilst the NPV remained high at every threshold. This increases its clinical utility. Two thirds of asymptomatic high-risk women had levels under $10 \mathrm{ng} / \mathrm{ml}$; in these 1000 women, only 10 (1\%) delivered before 30 weeks, independent of cervical length. Thus their risk was no higher than a healthy primigravida woman [12]

Tests proved equally good in women presenting with symptoms. At high levels $(>500 \mathrm{ng} / \mathrm{ml})$, compared to the old qualitative tests, positive likelihood ratios (4 to 14), relative risks (4 to 26) and PPV (20 to $46 \%$ ) all improved when predicting delivery within two weeks [14].

In January 2016 the predictive value of qfFN in both symptomatic and asymptomatic women between 18 and 21 weeks gestation was validated, demonstrating a similar predictive value to that of the previously defined standard of 22 weeks [16]. This allows earlier risk assessment and thus potential intervention. It was demonstrated that a qfFN of less than $10 \mathrm{ng} / \mathrm{ml}$ confers a risk of sPTB comparable to that of the background population (4\% versus 3.3\%) [16].

Clinical decisions are not dichotomised into low or high risk, but are likely to vary across the risk range. A calculated risk $<5 \%$ may guide a more conservative approach, avoiding unnecessary admission or inutero transfer. With a higher result, management can be appropriately targeted. In practice, a low threshold $(<10 \mathrm{ng} / \mathrm{ml})$ can reliably 'rule out' complex or expensive interventions (eg. IUT), such that they can be reserved for those with the highest levels, using a high threshold to 'rule in'.

\section{Cervical length}

Cervical shortening, effacement and dilation are integral parts of the normal process of labour and, when seen in women before 32 weeks gestation, can indicate a risk of early delivery. Transvaginal ultrasound (TVUS) measurement of cervical length (CL) between 14 and 24 weeks of gestation is a sensitive predictor of preterm birth in both high and low risk pregnancies [17].

The synergistic value of $\mathrm{qfFN}$ and $\mathrm{CL}$ provides exciting new opportunities within prediction of preterm birth. A recent meta- 
analysis confirmed that a combined approach can be used to reassure and guide management, reclassifying symptomatic women to a low risk cohort in whom expensive and potentially dangerous interventions can be avoided [18]. In a retrospective analysis of samples from 350 symptomatic women, qfFN added predictive value to women who had been selected by short CL $(<30 \mathrm{~mm})$. Bruijn et al. illustrated that as qfFN increases, so too does the risk of delivery within seven days ( 23 fold with levels $>500 \mathrm{ng} / \mathrm{ml}$ ) [13].

Based on results from a prospective secondary analysis of women enrolled in the EQUIPP study ( $\mathrm{n}=1249)$, Khurt et al. have developed and validated an exciting, highly accurate predictive algorithm using qfFN and CL to predict sPTB in both symptomatic and asymptomatic high-risk women. They have formulated an app for widespread, "on the go" use $[19,20]$. These interesting developments provide a platform through which clinical decisions can be more targeted.

A number of other commercially available biochemical tests for prediction of preterm birth are also available.

\section{Actim partus}

Actim Partus, a qualitative test, measures phosphorylated insulinlike growth factor binding protein (phIGFBP-1), a protein produced by placental decidual cells and released into the CVF after disruption to the choriodecidual interface.

A systematic review and meta-analysis published this year assessed the accuracy of cervical phIGFBP-1 to predict PTB in both symptomatic and asymptomatic women. Overall, Actim Partus has a low predictive accuracy for PTB $<34$ and $<37$ weeks gestation in both symptomatic and asymptomatic women (pooled sensitivities and specificities ranging from $14 \%$ to $47 \%$ and $76 \%$ to $93 \%$ ) and for delivery within 7 and 14 days amongst symptomatic women (pooled sensitivities and specificities varying between $60 \%$ and $80 \%$, and $77 \%$ and $81 \%$ ) [21].

However, a negative Actim Partus test result among women symptomatic of preterm labour has low to moderate predictive accuracy to identify those who are not at risk of delivering within the next 48 hours (summary negative likelihood ratio 0.28 in all women). Whilst it was concluded that there is not sufficient evidence to recommend routine use of Actim Partus in either symptomatic or asymptomatic women, Conde-Agudelo et al. suggest within their meta-analysis (2016) that cervical phIGFBP-1 has the potential utility to identify patients in TPTL who will not deliver within 48 hours [21].

Actim Partus also offers the advantage of not being affected by recent sexual intercourse or contamination with urine, lower cost and faster testing compared to the old fFN test [22].

Therefore further studies are required to evaluate the test's predictive ability within 48 hours and 7 days in symptomatic women, particularly those with a $\mathrm{CL}<30 \mathrm{~mm}$ [22]. The predictive qualities of Actim Partus are similar to the old qualitative fFN test for delivery in the short term.

\section{PartoSure}

PartoSure is a bedside test to detect the presence of placental alpha macroglobulin (PAMG-1) in the CVF. PAMG-1 is a glycoprotein usually found in high concentrations in the amniotic fluid with corresponding low levels in the CVF. A recent study $(n=203)$ demonstrated the efficacy of PartoSure in predicting sPTB within seven days (sensitivity $80 \%$, specificity 95\%, NPV 96\% and PPV 76\%) [23]. The short term predictive potential of PAMG-1 is promising, although its ability to predict delivery $>14$ days from testing is yet to be determined.

In the future these biochemical markers may work well in synergy, as they show potential for determining immediate risk of delivery. However, further studies are needed to confirm this promise.

\section{Prevention}

As predictive models become more sophisticated and available at the point of care, the onus is on the clinician to utilise and translate this into improved patient care.

The algorithm by Khurt et al. [20] simplifies an overwhelming number of variables into a risk value, which can be easily interpreted within the clinical context. The next step must be to target identified high-risk patients with the appropriate interventions.

Current options include prophylactic management with cerclage, progesterone or the Arabin pessary, and reactive interventions such as tocolysis to allow administration of ACS, IUT and magnesium sulphate, all aimed at improving neonatal outcome.

\section{Cervical cerclage}

Cervical cerclage, a suture placed around the cervix with the aim of providing mechanistic support and a barrier for ascending pathogens is a common prophylactic intervention for preterm birth in highrisk women. Cervical cerclage is indicated in patients with recurrent pregnancy loss (history indicated), those with a short cervix $(<25 \mathrm{~mm})$ on TVUS (ultrasound-indicated) and those with painless cervical dilation resulting in bulging fetal membranes (rescue cerclage).

The 2015 NICE guidelines recommend offering cervical cerclage to women with a history of sPTB between 16 and 34 weeks, and in whom TVUS reveals a cervical length $<25 \mathrm{~mm}$ [11]. A recent RCT $(\mathrm{n}=248)$ conducted by Simcox et al. compared history-indicated placement of cervical cerclage with ultrasound-indicated placement in women at high risk of PTB. They found that offering ultrasound surveillance of CL and cerclage for those with a short cervix did not result in reduction of preterm birth before 34 weeks when compared with a suture placed electively, based on history alone [24].

A multi-centre, randomised controlled trial (C-STICH) is currently ongoing to examine the effect of using a monofilament suture material compared with a braided suture on pregnancy loss rate and neonatal mortality. Whilst a survey of consultants in the UK showed most used braided threads, questions have been raised regarding a potential for increased risk of infection with this material. As infection and inflammation are recognised pathways associated with PTB, the results of this study are eagerly awaited [25].

\section{Rescue cerclage}

In cases of premature cervical dilation and bulging fetal membranes, a rescue cerclage may be inserted in the attempt to reduce the bulging membranes and re-seal the cervix. There is conflicting evidence regarding the success of the emergency 'rescue' cerclage, and a lack of controlled trials [26]. Daskalakis et al. evaluated the efficacy of rescue cerclage in 29 low-risk women with dilated cervix and protruding fetal membranes. The mean prolongation of pregnancy was 8.8 weeks in the cerclage group compared to 3.1 weeks in the bed-rest group. Neonatal survival was significantly improved in the cerclage group (96\% versus $51.7 \%$ in the bed-rest group ( $\mathrm{P}=0.025)$ ( $\mathrm{RR} 0.09,95 \% \mathrm{CI} 0.01-0.76)$ ). Their findings show that emergency cerclage between 18 and 26 weeks of gestation can promote a three-fold reduction in the preterm delivery 
rate before 32 weeks, which has an associated positive (3.5-fold) impact on neonatal survival rate [26]. The 2015 NICE guidelines do recommend 'considering' rescue cervical cerclage for women between 16 and 27 weeks with a dilated cervix and exposed membranes, as long as there are no signs of bleeding, infection or uterine contractions [11].

\section{Reinforcing cerclage (second cerclage)}

A retrospective cohort study undertaken in 2012 examined the role of reinforcing vaginal cerclage after a failed initial cerclage in reducing preterm delivery in women with evidence of bulging membranes. The women who received reinforcing cerclage were more likely to deliver early compared with those managed expectantly. Indeed, $92 \%$ of the reinforcing cerclage group delivered at $<32$ weeks gestation compared to $42 \%$ in the expectant management group $(\mathrm{P}=0.01)$. It was concluded that rescue cerclage following primary cerclage failure hastened preterm delivery [27].

\section{Transabdominal cerclage}

Whilst a less-invasive vaginal cerclage is the preferred option, recent evidence suggests that women with either previous failed vaginal suture or extensive surgery to the cervix may benefit from higher placement of the stitch abdominally. It has been proposed that this may provide superior mechanical support to the cervix.

The MAVRIC trial (multicentre randomised trial of high versus low versus abdominal cerclage in women with a previous failed stitch) demonstrated that cerclage placed via the abdominal route (TAC) performed superiorly to both low and high vaginal cerclage in reducing late miscarriage and early PTB in women with a previous failed vaginal cerclage [28].

\section{Progesterone therapy}

Increased activity of endogenous progesterone is necessary for the development and maintenance of uterine quiescence during pregnancy. As such, exogenous progesterone has been a longstanding preventative therapy. In a recent systematic review, Dodd et al. examined 36 RCTs evaluating the use of progesterone therapy for women at high risk of sPTB. Although methods of administration (intramuscular or vaginal) and dosage varied, they concluded that for women with a history of $\mathrm{sPTB}$, antenatal progesterone therapy was associated with a significant reduction in $\mathrm{SPTB}<34$ weeks ( 5 studies; 602 women; average RR 0.55 , $95 \%$ CI 0.42 to 0.74 ) and $<37$ weeks (10 studies; 1750 women; average RR 0.50, 95\% CI 0.33 to 0.75) [29].

However, in a recent study of over 1200 high-risk women randomised to vaginal progesterone, evaluating both short and long term outcomes, there was no benefit of progesterone. For example, mean cognitive scores in both groups were identical at 2 years of age (97.3 vs. 97.7). The authors concluded that vaginal progesterone was not associated with a reduction in risk of PTB or of composite adverse neonatal outcomes [30]. Given this is at variance with the metaanalysis, further research needs to arbitrate the truth.

Furthermore, the benefit of antenatal progesterone is not reproducible in multiple pregnancies. The STOPPIT trial published in 2009 , randomised 500 women with twin pregnancy to daily vaginal progesterone or placebo for 10 weeks from 24 weeks of gestation. The rate of adverse events did not differ between the two groups [31]. Current NICE guidelines recommend prophylactic progesterone to women without history of sPTB and in whom a CL of $<25 \mathrm{~mm}$ is identified on TVUS between 16 and 24 weeks [11].

\section{The Arabin Pessary}

The Arabin Pessary is a flexible silicon ring designed to encircle and support the cervix, altering the inclination of the cervical canal and the weight distribution of the uterus with the aim of preventing premature cervical shortening and preterm birth [32]. In the first multicentre RCT evaluating the pessary, Goya et al. randomised women with singleton pregnancies and cervical length $<25 \mathrm{~mm}$ to pessary or no pessary. They observed a reduced rate of sPTB $<34$ weeks gestation compared with controls ( $6 \%$ vs. $27 \%$, OR 0.18 , CI $0.08-0.37)$. There was a significant difference in the occurrence of the composite neonatal morbidity and mortality outcome (OR 0.14, CI 0.04-0.39) [33]. In contrast, Hui et al. randomised women with a short cervix $<25 \mathrm{~mm}$ between 20 and 24 weeks to pessary or expectant management. They found that the prophylactic pessary did not reduce the rate of PTB before 34 weeks (9.4\% in the pessary group, $5.5 \%$ in the control group $(\mathrm{p}=0.46))$ [34].

The recent RCT by Kypros et al. evaluating the value of the pessary in unselected twin pregnancies concluded that cervical pessary does not reduce the rate of SPTB in twin pregnancy [35]. The ProTWIN study, a multicentre open-label RCT, randomised women with multiple pregnancy between 12 and 20 weeks gestation to pessary or control. It was concluded that the pessary did not reduce poor perintatal outcome in these women [36]. However, following on from their 2012 singleton pregnancy study, Goya et al. recently undertook a multicentre RCT to evaluate whether the pessary reduces the rate of preterm birth in twin pregnancies with a short cervix $(n=137)$. They demonstrated that the rate of $\mathrm{sPTB}<34$ weeks was significantly reduced (RR $0.41,95 \% \mathrm{CI}$ $0.22-0.76$ ) [37]. The STOPPIT2 trial is currently underway to further evaluate the role of the pessary in preventing SPTB in twins.

It is clear that the role of the Arabin Pessary in preventing sPTB is yet to be fully explored, however further trials are underway to evaluate its worth, and it remains a promising approach in the prevention of sPTB.

There is further need for well-controlled prospective trials to compare cerclage, progesterone and the Arabin pessary as the current evidence is inconsistent and all have shown some potential. One such study (the SUPPORT trial) is currently being rolled out in the UK.

\section{Antibiotics}

Due to the association between inflammation/infection and sPTB, antibiotics have been explored as an option for treatment in high and low risk women.

A meta-analysis by Simcox et al. did not demonstrate reduction in risk of PTB when treating asymptomatic women with antibiotics [38]. A Cochrane review, updated in 2013 revealed that whilst antibiotic therapy was efficacious at eliminating bacterial vaginosis and restoring normal vaginal flora, there was no evident reduction in the rate of PTB for any therapeutic regimen. Alarmingly, the review reported an increase in neonatal deaths for infants of women receiving any prophylactic antibiotics when compared to placebo (RR 1.57, 95\% CI 1.03 to 2.40 ) [39]. Furthermore, treatment with macrolide antibiotics was shown to increase neonatal death (RR 1.11, 95\% CI 1.01 to 1.20), functional impairment and cerebral palsy. Some trials even show increased risks of delivery. For example, in the PREMET study, Shennan et al. also reported an increase in risk of sPTB associated with use of metronidazole in asymptomatic high-risk women [40].

The 2015 WHO guidelines do not recommend routine antibiotic administration for women in preterm labour with intact amniotic 
membranes and no clinical signs of infection. However for women with PPROM, administration of erythromycin is recommended [41].

\section{Reactive intervention}

\section{Steroids}

Administration of antenatal corticosteroids (ACS) to women at high risk of PTB has been shown to enhance fetal lung maturity and reduce the frequency of respiratory distress syndrome (RDS) in neonates, as well as reduce periventricular haemorrhage and necrotising enterocolitis [11]. ACS now form an integral part of the management of TPTL, as recommended in the latest NICE guideline (2015).

Timing of steroid administration is crucial to conferring optimum benefit, something that is not always fully appreciated [42]. Sub-group analysis of a 2006 Cochrane review revealed that ACS bestow greatest benefit (significant reduction in combined fetal and neonatal deaths) when delivery occurs within $48 \mathrm{hrs}$ post-administration. In contrast, babies delivered seven days after administration demonstrated lower birth weight (mean difference $-147 \mathrm{~g}$, CI -291 to $-2 \mathrm{~g}$ ), head circumference and length. Moreover, concerns have been raised about possible links between impaired fetal growth and type 2 Diabetes Mellitus and cardiovascular disease [43]. The majority (80\%) of women who present with TPTL do not go on to deliver within seven days of presentation [5]. These women are therefore receiving steroids that do not confer benefit, and may in fact do harm.

Whilst current guidelines recommend women presenting in TPTL should receive ACS [11], new evidence highlights the importance of delivery within 48 hours of treatment [41].

The beneficial effects of early ACS are not seen in women who deliver close to term ( $>34$ weeks). The Cochrane review observed a worrying trend toward fetal and neonatal death in infants who received ACS but delivered after 36 weeks gestation (RR 3.25; 95\% CI $0.99-$ 10.66) [10].

New evidence continues to explore the role of ACS during the late preterm period. A recent study from February $2016(n=2827)$ found a significant reduction in the rate of neonatal respiratory complications in women receiving betamethasone compared to placebo between 34 and $36+5$ weeks. (RR $0.80,95 \%$ CI 0.66 to $0.97 \mathrm{P}=0.02$ ), when administered after 34 weeks [44]. Further studies and consensus are needed to expand upon the importance of steroids beyond the 34 week gestation, especially in view of this positive effect.

In light of concerns regarding ACS and the possible association with impaired fetal growth, cardiovascular disease and insulin resistance, it is important to carefully consider the impact of repeat courses. A review in 2011 demonstrated no significant differences between single and repeat-course groups in terms of fetal or neonatal deaths. Indeed, a combined outcome (infant mortality and serious morbidity) was significantly reduced in the infants of women treated with repeat courses of corticosteroids compared to controls (RR 0.84, 95\% CI 0.75-0.94). Infants who received a repeat course had on average slightly lower birth weight (mean difference -75.79 g, 95\% CI - 117.63 to -33.96). However, long term outcomes were similar [45]. The 2015 WHO guidelines therefore recommend a single repeat dose of ACS if PTB does not occur within 7 days after the initial dose, and subsequent PTB remains likely [41].

Administration of ACS within 48 hours of preterm delivery is undoubtedly beneficial for the unborn neonate but this timeframe is imperative. Therefore, accurate predictive tools such as the algorithm developed by Khurt et al. [20] are paramount in determining whom to treat and when.

An abstract presented at the Society for Maternal Fetal Medicine in 2016 suggested that timely administration of betamethasone for women at risk for late preterm delivery ( 34 to $36+6$ weeks) saw a reduction in neonatal respiratory morbidity and the need for surfactant [46].

\section{Magnesium sulphate}

The neuroprotective effects of antenatal magnesium sulphate to premature infants have been established [47]. There is no consensus regarding the optimal dosage and timing regimen of magnesium sulphate administration. However, a 2009 Cochrane review evaluating its use for prevention or treatment of pre-eclampsia and eclampsia, with secondary infant outcomes concluded that antenatal magnesium sulphate for women at risk of impending preterm birth substantially reduced the risk of cerebral palsy (RR $0.68,95 \%$ CI 0.54 to 0.87 ), with a significant reduction in the rate of gross motor dysfunction (RR $0.61 \%, 95 \%$ CI 0.44 to 0.85 ) [47]. This clearly demonstrates the value of secondary analysis, especially when considering rare but important outcomes such as cerebral palsy.

No significant effects were observed on overall paediatric mortality or other neurological disabilities in the first few years of life [47]. Questions still remain regarding optimal dosage and timing, the gestational age at which magnesium sulphate is most efficacious and the long-term neuroedevelopmental effects. A large RCT is currently underway in Scandinavia to investigate magnesium sulphate administered to high-risk women between 24 and 32 weeks of gestation [48].

\section{Tocolysis}

Tocolytic therapy itself has not been shown to improve neonatal outcome [49]. Recent WHO guidelines stipulate that tocolytic treatments (acute and maintenance) are not recommended for women at risk of imminent preterm birth for the purpose of improving newborn outcomes, but may be considered as an intervention to gain time for completion of a course of ACS [41].

\section{Conclusion}

The impact of preterm birth remains significant and the prevalence constant. In recent years, there have been substantial developments in both prediction and prevention. Tools to predict preterm birth are now available clinically. There remains uncertainty as to the best intervention but there are a number of promising candidates. Key to implementation is targeting the correct interventions to the correct patients. Current research needs to establish optimal management strategies and this will be achieved through understanding mechanisms. It is an exciting field with many new developments and it is important that all clinicians facilitate access to their populations for this research.

\section{Funding}

Professor A Shennan receives financial assistance to provide educational talks on preterm birth from Hologic, USA.

\section{References}

1. Kleinrouweler CE, Cheong-See FM, Collins GS, Kwee A, Thangaratinam S, et al (2015) Prognostic models in obstetrics: Available, but far from applicable. Am J Obstet Gynecol 214: 79-90. [Crossref]

2. Blencowe H, Cousens S, Oestergaard MZ, Doris Chou D, Moller AB. (2012) National, 
regional, and worldwide estimates of preterm birth rates in the year 2010 with time trends since 1990 for selected countries: A systematic analysis and implications. The Lancet 379: 2162-2172.

3. March of Dimes PMNCH Save the Children WHO (2012) Born Too Soon: The Global Action Report on Preterm Birth.

4. Romero R, Dey SK, Fisher SJ (2014) Preterm labor: one syndrome, many causes. Science 345: 760-765. [Crossref]

5. Peaceman AM, Andrews WW, Thorp JM, Cliver SP, Lukes A, et al. (1997) Fetalfibronectin as a predictor of preterm birth in patients with symptoms: a multicenter trial.Am J Obstet Gynecol 177: 13-18. [Crossref]

6. Goffinet F (2005) Primary predictors of preterm labour. BJOG 112 Suppl 1: 38-47. [Crossref]

7. Goldenberg RL, Culhane JF, Iams JD, Romero R (2008) Epidemiology and causes of preterm birth. Lancet 371: 75-84. [Crossref]

8. Cnattingius S (2004) The epidemiology of smoking during pregnancy: smoking prevalence, maternal characteristics, and pregnancy outcomes. Nicotine Tob Res 6 Suppl 2:S125-40. [Crossref]

9. Levine LD, Sammel MD, Hirshberg A, Elovitz MA, Srinivas SK (2015) Does stage of labor at time of cesarean delivery affect risk of subsequent preterm birth? Am J Obste Gynecol 212: 360. [Crossref]

10. Roberts D, Dalziel S (2006) Antenatal corticosteroids for accelerating fetal lung maturation for women at risk of preterm birth. Cochrane Database Syst Rev: CD004454. [Crossref]

11. National Institute for Health and Care Excellence (2015) Preterm labour and birth; NICE guideline NG25.

12. Abbott DS, Hezelgrave NL, Seed PT, Norman JE, David AL, et al. (2015) Quantitative fetal fibronectin to predict preterm birth in asymptomatic women at high risk. Obstet Gynecol 125: 1168-1176. [Crossref]

13. Bruijn M, Vis JY, Wilms FF, Oudijk MA, Kwee A, et al. (2015) Quantitative fetal fibronectin testing in combination with cervical length measurement in the prediction of spontaneous preterm delivery in symptomatic women. BJOG.

14. Abbott DS, Radford SK, Seed PT, Tribe RM, Shennan AH (2013) Evaluation of a quantitative fetal fibronectin test for spontaneous preterm birth in symptomatic women. Am J Obstet Gynecol 208: 122. [Crossref]

15. Kurtzman J, Chandiramani M, Briley A, Poston L, Das A, et al. (2009) Quantitative fetal fibronectin screening in asymptomatic high-risk patients and the spectrum of risk for recurrent preterm delivery. Am J Obstet Gynecol 200: 263. [Crossref]

16. Hezelgrave NL, Abbott DS, Radford SK, Seed PT, Girling JC, et al. (2016) Quantitative Fetal Fibronectin at 18 Weeks of Gestation to Predict Preterm Birth in Asymptomatic High-Risk Women. Obstet Gynecol 127: 255-63. [Crossref]

17. Grimes-Dennis J, Berghella V (2007) Cervical length and prediction of preterm delivery. Curr Opin Obstet Gynecol 19: 191-195. [Crossref]

18. DeFranco EA, Lewis DF, Odibo AO (2013) Improving the screening accuracy for preterm labor: Is the combination of fetal fibronectin and cervical length in symptomatic patients a useful predictor of preterm birth? A systematic review. Am J Obstet Gynecol 208: 233. [Crossref]

19. Kuhrt K, Smout E, Hezelgrave N, Seed PT, Carter J, et al. (2013) The development and validation of a new tool to predict spontaneous preterm birth in high-risk women using quantitative fetal fibronectin and cervical length. Ultrasound Obstet Gynecol 47:104109. [Crossref]

20. Kuhrt K, Hezelgrave N, Foster C, Seed PT, Shennan AH, et al. (2015) Development and validation of a predictive tool for spontaneous preterm birth, incorporating quantitative fetal fibronectin, in symptomatic women. Ultrasound Obstet Gynecol 47: 210-216. [Crossref]

21. Conde-Agudelo A, Romero R (2016) Cervical phosphorylated insulin-like growth factor binding protein-1 test for the prediction of preterm birth: a systematic review and metaanalysis. Am J Obstet Gynecol 214: 57-73. [Crossref]

22. Corabian P (2008) The ActimPartus versus the TLI-IQ System as rapid response tests to aid in diagnosing preterm labour in symptomatic women.

23. Nikolova T, Bayev O, Nikolova N, Di Renzo GC (2014) Evaluation of a novel placental alpha microglobulin-1 (PAMG-1) test to predict spontaneous preterm delivery. $J$ Perinat Med 42: 473-477. [Crossref]

24. Simcox R, Seed PT, Bennett P, Teoh TG, Poston L, et al. (2009) A randomized controlled trial of cervical scanning vs history to determine cerclage in women at high risk of preterm birth (CIRCLE trial). Am J Obstet Gynecol 200: 623. [Crossref]

25. University of Birmingham (2015) About the C-Stich trial [online]. Available from http://www.birmingham.ac.uk/research/activity/mds/trials/bctu/trials/womens/C-Stich/ about.aspx (Accessed 23 February 2016).

26. Daskalakis G, Papantoniou N, Mesogitis S, Antsaklis A (2006) Management of cervica insufficiency and bulging fetal membranes. Obstet Gynecol 107: 221-226. [Crossref]

27. Simcox R, Shennan A (2012) Reinforcing cerclage in the prevention of preterm birth in women at high risk: a retrospective case-controlled study.Aust N Z J Obstet Gynaecol 52: 224-228. [Crossref]

28. Carter J (2015) MAVRIC: Multicentre Abdominal vs Vaginal Randomised Investigation of Cerclage. BJOG 1221-1227.

29. Dodd JM, Jones L, Flenady V, Cincotta R, Crowther CA, et al. (2006) Prenata administration of progesterone for preventing preterm birth in women considered to be at risk of ppreterm birth (Review). Cochrane Database Syst Rev.

30. Norman JE, Marlow N, Messow CM, Shennan A, Bennett PR,et al. (2016) Vagina progesterone prophylaxis for preterm birth (the OPPTIMUM study): a multicentre, randomised, double-blind trial. Lancet 6736: 1-11.

31. Norman JE, Mackenzie F, Owen P, Mactier H, Hanretty K, et al. (2009) Progesterone for the prevention of preterm birth in twin pregnancy (STOPPIT): a randomised, doubleblind, placebo-controlled study and meta-analysis. Lancet 373: 2034-2040. [Crossref]

32. Arabin B, Alfirevic Z (2013) Cervicalpessaries for prevention of spontaneous preterm birth: Past, present and future. Ultrasound Obstet Gynecol 42: 390-399. [Crossref]

33. Goya M, Pratcorona L, Merced C, Rodó C, Valle L, et al. (2012) Cervicalpessary in pregnant women with a short cervix (PECEP): an open-label randomised controlled trial. Lancet 379: 1800-1806. [Crossref]

34. Hui SY, Chor CM, Lau TK, Lao TT, Leung TY (2013) Cerclagepessary for preventing preterm birth in women with a singleton pregnancy and a short cervix at 20 to 24 weeks: a randomized controlled trial. Am J Perinatol 30: 283-288.[Crossref]

35. Nicolaides KH, Syngelaki A, Poon LC, de PacoMatallana C, Plasencia W, et al (2015) Cervical pessary placement for prevention of preterm birth in unselected twin pregnancies: A randomized controlled trial. Am J Obstet Gynecol 214: 3. [Crossref]

36. Liem S, Schuit E, Hegeman M, Bais J, de Boer K, et al. (2013) Cervicalpessaries for prevention of preterm birth in women with a multiple pregnancy (ProTWIN): A multicentre, open-label randomised controlled trial. Lancet 382: 1341-1349. [Crossref]

37. Goya M, de la Calle M, Pratcorona L, Merced C, Rodó C, et al. (2015) Cervicalpessary to prevent preterm birth in women with twin gestation and sonographic short cervix: a multicenter randomized controlled trial (PECEP-Twins). Am J Obstet Gynecol 214:145-152. [Crossref]

38. Simcox R, Sin WT, Seed PT, Briley A, Shennan AH (2007) Prophylactic antibiotics for the prevention of preterm birth in women at risk: a meta-analysis. Aust $N$ Z J Obstet Gynaecol 47: 368-377. [Crossref]

39. King J, Flenady V (2002) Prophylactic antibiotics for inhibiting preterm labour with intact membranes. Cochrane Database Syst Rev: CD000246. [Crossref]

40. Shennan A, Crawshaw S, Briley A, Hawken J, Seed P, et al. (2006) A randomised controlled trial of metronidazole for the prevention of preterm birth in women positive for cervicovaginal fetal fibronectin: The PREMET Study. BJOG 113:65-74. [Crossref]

41. World Health Organisation (2015) WHO recommendations on interventions to improve preterm birth outcomes.

42. Freeman CI, Hezelgravem NL, Shennan AH (2015) Antenatal steroids for fetal lung maturity: Time to target more frequent doses to fewer women? Obstetric Medicine 8: 172-176.

43. Kelly BA, Lewandowski AJ, Worton SA, Davis EF, Lazdam M, et al. (2012) Antenatal glucocorticoid exposure and long-term alterations in aortic function and glucose metabolism. Pediatrics 129: e1282-1290. [Crossref]

44. Gyamfi-Bannerman C, Thom EA, Blackwell SC, Tita AT, Reddy UM, et al. (2016) Antenatal Betamethasone for Women at Risk for Late Preterm Delivery. $N$ Engl J Med 374: 1311-1320. [Crossref]

45. Crowther CA, McKinlay CJ, Middleton P, Harding JE (2011) Repeat doses of prenata corticosteroids for women at risk of preterm birth for improving neonatal health outcomes. Cochrane Database Syst Rev: CD003935. [Crossref]

46. Gyamfi-Bannerman C (2016) Antenatal Late Preterm Steroids (ALPS): a randomized 


\section{trial to reduce neonatal respiratory morbidity. AmJ Obstet Gynecol.}

47. Doyle LW, Crowther CA, Middleton P, Marret S(2009) Magnesium sulphate for women at risk of preterm birth for neuroprotection of the fetus. Cochrane Database Syst Rev: CD004661. [Crossref]

48. Huusom LD, Brok J, Hegaard HK, Pryds O, Secher NJ (2012) Does antenatal magnesium sulfate prevent cerebral palsy in preterm infants? The final trial? Acto Obstet Gynecol Scand 91: 1346-1347. [Crossref]

49. Haas DM, Caldwell DM, Kirkpatrick P, McIntosh JJ, Welton NJ (2012) Tocolytic therapy for preterm delivery: systematic review and network meta-analysis. BMJ 345 : e6226. [Crossref]

Copyright: (C2016 Ross MGN. This is an open-access article distributed under the terms of the Creative Commons Attribution License, which permits unrestricted use, distribution, and reproduction in any medium, provided the original author and source are credited. 